\title{
Erratum to: Southern Africa: the Highest Priority Region for HIV Prevention and Care Interventions
}

\author{
Sten H. Vermund ${ }^{1,2} \cdot$ Emily K. Sheldon $^{1} \cdot$ Mohsin Sidat $^{3}$
}

Published online: 4 June 2015

(C) Springer Science+Business Media New York 2015

\section{Erratum to: Curr HIV/AIDS Rep (2015) 12:191-195 DOI 10.1007/s11904-015-0270-z}

We regret that the original version of this article contained mistakes. First, our reference 1 reflects CAPRISA HIV incidence data largely on non-pregnant women. The reference that reports on pregnant women in rural KwaZuluNatal is:

MacQueen KM, Karim QA. Practice brief: adolescents and HIV clinical trials: ethics, culture, and context. $J$ Assoc Nurses AIDS Care 2007;18(2):78-82.

Second, the data in Table 1 in our paper are from Vulindlela, a hyperendemic zone of South Africa, and must not be construed to represent southern Africa as a whole. These data are in provenance of the CAPRISA investigators, Drs. Ayesha Kharsany and Quarraisha Abdool Karim. Drs. Kharsany and Abdool Karim have shared with me public sector data that make the point of Table 1 in the manuscript much more effectively, since they represent South Africa as a whole and are

The online version of the original article can be found at http://dx.doi.org/ 10.1007/s11904-015-0270-z.

Sten H. Vermund

sten.vermund@vanderbilt.edu

1 Vanderbilt Institute of Global Health, Vanderbilt University School of Medicine, 2525 West End Ave., Suite 750, Nashville, TN 37203 , USA

2 Department of Pediatrics, Vanderbilt University School of Medicine, Nashville, TN, USA

3 Office of the Dean, School of Medicine, Universidade Eduardo Mondlane, Maputo, Mozambique therefore better representative of the magnitude of the southern African epidemic:

Table 1 National antenatal seroprevalence data from South Africa by age of woman and year of sample

\begin{tabular}{llllllll}
\hline Age in years & \multicolumn{7}{l}{ Year of sample } \\
\cline { 2 - 8 } & 2001 & 2002 & 2003 & 2004 & 2005 & 2006 & 2007 \\
\hline $15-19$ & 15.4 & 14.8 & 15.8 & 16.1 & 15.9 & 13.7 & 12.9 \\
$20-24$ & 28.4 & 29.1 & 30.3 & 30.8 & 30.6 & 28.0 & 28.1 \\
$25-29$ & 31.4 & 34.5 & 35.4 & 38.5 & 39.5 & 38.7 & 37.9 \\
$30-34$ & 25.6 & 29.5 & 30.9 & 34.4 & 36.4 & 37.0 & 40.2 \\
$35-39$ & 19.3 & 19.8 & 23.4 & 24.5 & 28.0 & 29.3 & 33.2 \\
$\geq 40$ & 9.8 & 17.2 & 15.8 & 17.5 & 19.8 & 21.3 & 21.5 \\
All ages & 24.8 & 26.5 & 27.9 & 29.5 & 30.2 & 29.1 & 28.0
\end{tabular}

Data for 2001 are from THE NATIONAL HIV AND SYPHILIS ANTE NATAL SERO-PREVALENCE SURVEY IN SOUTH AFRICA 2002 Pretoria: National Department of Health, South Africa, 2003. Accessible here: http://www.gov.za/sites/www.gov.za/files/hivsyphilis_0.pdf (accessed May 6, 2015).

Data from 2002 to 2004 are from the Directorate: Health Systems Research, Research Coordination and Epidemiology. NATIONAL HIV AND SYPHILIS ANTENATAL SERO-PREVALENCE SURVEY IN SOUTH AFRICA 2004: Pretoria: National Department of Health, South Africa, 2005. Accessible here: http://www.hst.org.za/sites/default/files/hivsyphilis04.pdf (accessed May 6, 2015).

Data from 2005 to 2007 are from THE NATIONAL HIV AND SYPHILIS PREVALENCE SURVEY SOUTH AFRICA 2007. Pretoria: National Department of Health, South Africa, 2008. Accessible here: http:/data.unaids.org/ pub/Report/2008/20080904_southafrica_anc_2008_en.pdf (accessed May 6, 2015).

The table was kindly crafted by Drs. Ayesha Kharsany and Quarraisha Abdool Karim. 